Supporting Information

\title{
Electrodeposition of Large Area, Angle-Insensitive Multilayered Structural Colors
}

Chengang Ji, ${ }^{1, \dagger}$ Saurabh Acharya, ${ }^{1, \dagger}$ Kaito Yamada, ${ }^{2}$ Stephen Maldonado, ${ }^{2,3, *}$ and L. Jay Guo ${ }^{1,2, *}$

${ }^{1}$ Department of Electrical Engineering and Computer Science, ${ }^{2}$ Applied Physics Program, ${ }^{3}$ Department of Chemistry, The University of Michigan, Ann Arbor, Michigan 48109, USA

$\dagger$ C. Ji and S. Acharya contributed equally to this work

*Corresponding Author: guo@umich.edu, smald@umich.edu 


\section{S1. Chronopotentiometry Plots}

$\mathrm{Cu}_{2} \mathrm{O}$ films were electrodeposited on $\mathrm{Au} / \mathrm{n}^{+} \mathrm{Si}$ (111) substrates using an alkaline solution $(\mathrm{pH} \sim$ 10.9) containing $0.4 \mathrm{M} \mathrm{CuSO}_{4} \cdot 5 \mathrm{H}_{2} \mathrm{O}$ and $1.6 \mathrm{M}$ citric acid at $T=50{ }^{\circ} \mathrm{C}$ using a current density of $j=0.1 \mathrm{~mA} / \mathrm{cm}^{2}$. The thickness of the $\mathrm{Cu}_{2} \mathrm{O}$ layer was tuned to obtain the CMY colors by simply altering the electrodeposition time and the corresponding chronopotentiometry plots for three different thicknesses $(20,40,60 \mathrm{~nm})$ of $\mathrm{Cu}_{2} \mathrm{O}$ is shown in Figure $\mathrm{S} 1$. The consistent shape and form of these plots for the three samples indicates a uniform and consistent deposition among the different samples.

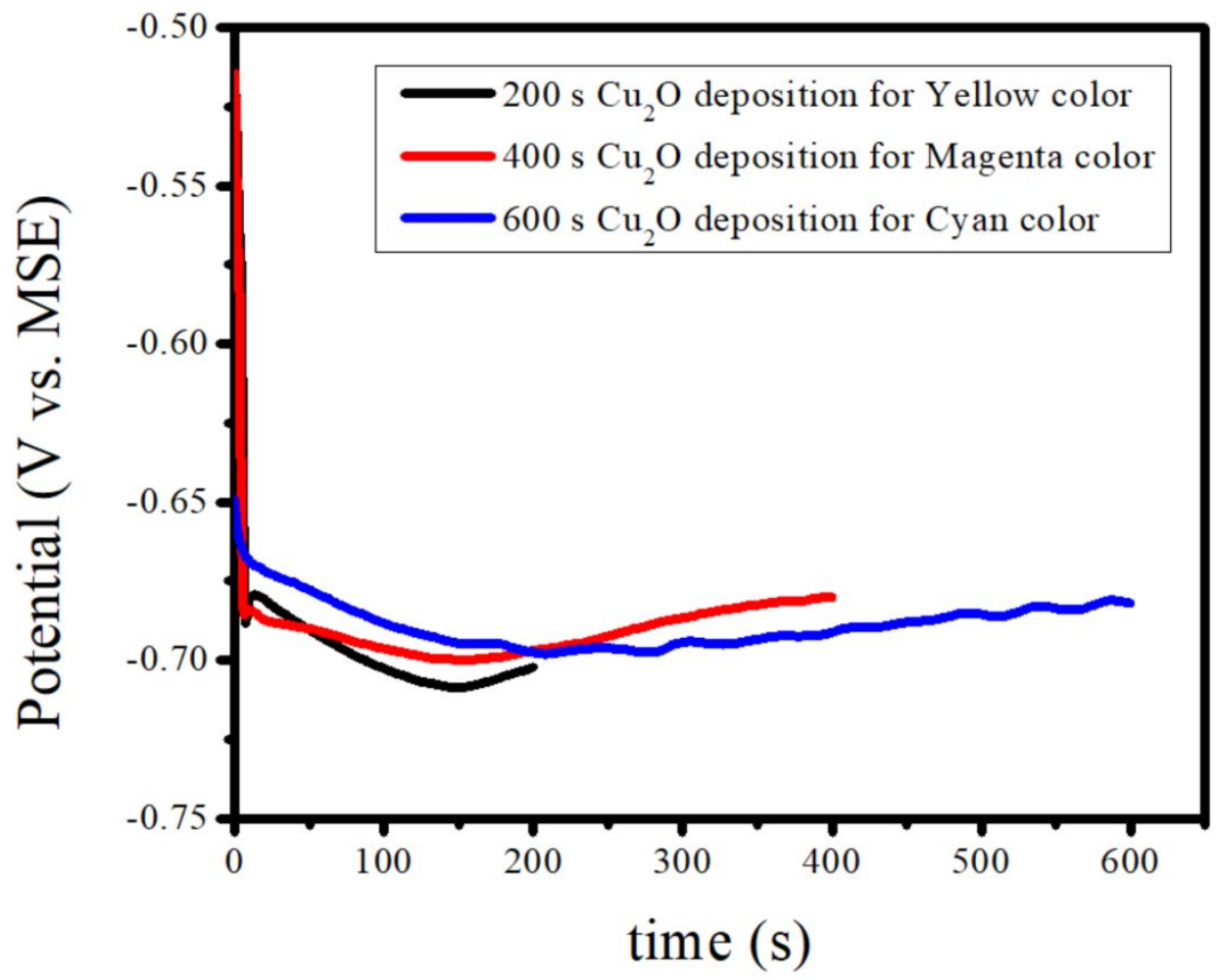

Figure S1. Chronopotentiometry plots of different thicknesses of $\mathrm{Cu}_{2} \mathrm{O}$ thin-films electrodeposited on $\mathrm{Au} / \mathrm{n}^{+} \mathrm{Si}(111)$ electrodes in an electrolyte containing $0.4 \mathrm{M} \mathrm{CuSO}_{4} \cdot 5 \mathrm{H}_{2} \mathrm{O}$ and $1.6 \mathrm{M}$ citric acid at $T=50{ }^{\circ} \mathrm{C}$ and using a current density of $j=0.1 \mathrm{~mA} / \mathrm{cm}^{2}$. 
The accuracy of the film thickness is a strength of electrodeposition. Specifically, by controlling the total coulombs passed we can control the thickness. The current resolution of the experiment defines the resolution of mass deposition. For example, assuming a current resolution of $5 \times 10^{-4}$ $\mathrm{C} \mathrm{s}^{-1}$ for a $1 \mathrm{~cm}^{2}$ electrode, the mass deposition rate for a $2 \mathrm{e}^{-}$reduction process of $\mathrm{Cu}_{2} \mathrm{O}$ is $\sim 0.6$ $\mathrm{nm} \mathrm{s}^{-1} \mathrm{~cm}^{-2}$. 


\section{S2. Issues Related to Electrodeposited Cu}

For the electrodeposition of the final top metal layer, the intent was to use the same bath for the $\mathrm{Cu}_{2} \mathrm{O}$ electrodeposition and just grow a capping $\mathrm{Cu}^{0}$ layer on top by increasing the current density to produce $\mathrm{Au} / \mathrm{Cu}_{2} \mathrm{O} / \mathrm{Cu}$ MDM stacks or even $\mathrm{Cu} / \mathrm{Cu}_{2} \mathrm{O} / \mathrm{Cu}$ MDM stacks. There is precedent for this approach in previous reports of electrodeposition of epitaxial metal-metal oxide layers by pulsed currents. ${ }^{1-5}$ However, while $\mathrm{Cu}^{0}$ layers were readily formed, all samples yielded $\mathrm{Cu}^{0}$ films that were of poor optical and electrical quality, showing significant lossy character and approximately 100x lower conductivity than thermally evaporated $\mathrm{Cu}$ films of similar thickness. Even though energy dispersive (EDS) and X-ray diffraction (XRD) spectra showed no detectable impurities and pure $\mathrm{Cu}$ character, the optical and electrical properties could not be improved for a film with a thickness below $20 \mathrm{~nm}$. Annealing these $\mathrm{Cu}$ films in $\mathrm{Ar}(\mathrm{g})$ at $T=200{ }^{\circ} \mathrm{C}$ increased the surface roughness of these films (Figure S2), possibly due to the diffusion of entrapped air/solvent in nanoscale voids in the $\mathrm{Cu}$ film. Accordingly, electrodeposited $\mathrm{Cu}$ thin films were not pursued further using this electrolyte.
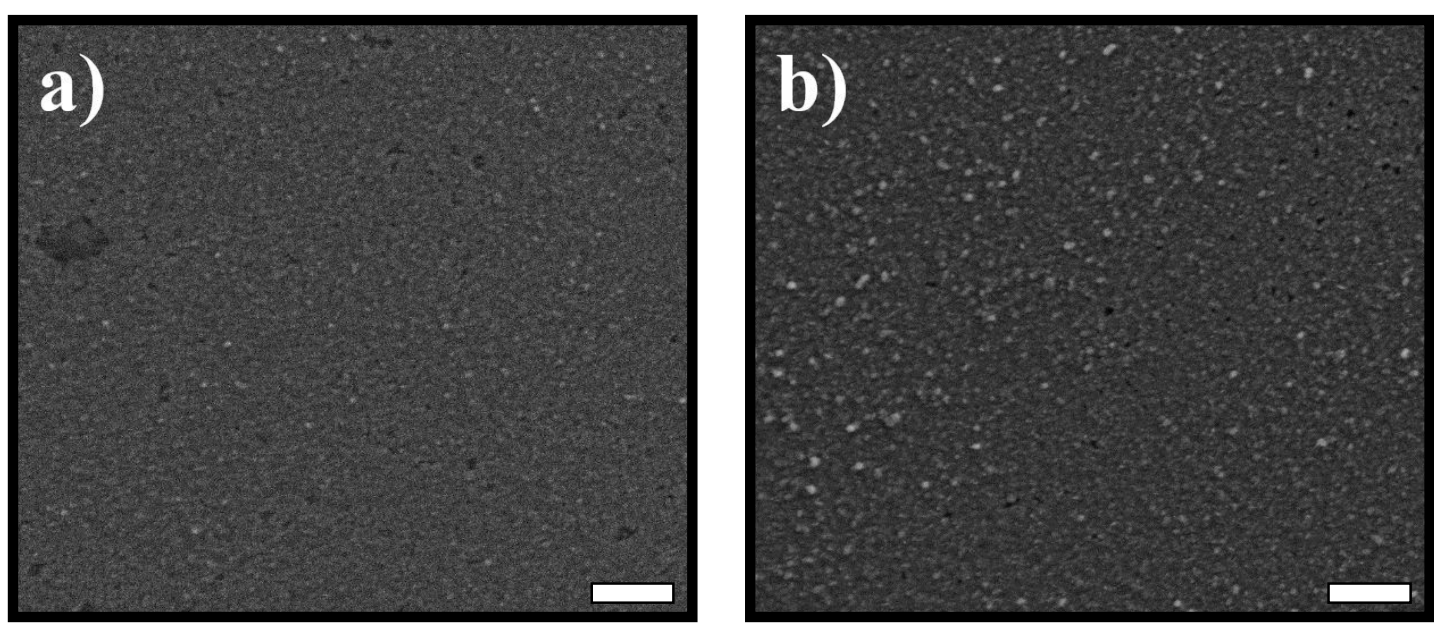

Figure S2. Scanning electron micrographs of a) as-deposited $\mathrm{Cu}$ film on a Si substrate b) $\mathrm{Cu}$ film annealed in $\operatorname{Ar}(\mathrm{g})$ at $T=200{ }^{\circ} \mathrm{C}$ for $t=120 \mathrm{~s}$. Scale bar $=2 \mu \mathrm{m}$. 


\section{S3. Thickness Uniformity of Electrodeposited Films}

The uniformity of the electrodeposited films is a major point of this work. Using the yellow colored device as an example, the reflectance spectra at four difference locations of the sample were measured and summarized in the Figure S3. It is evident that these spectra are very similar to each other, which indicates the great uniformity in thickness of each electrodeposited layer. In addition, the uniformity of the observed optical properties (color, reflectance) of the films over macroscopic dimensions (i.e. $6 \mathrm{~cm}^{2}$ curved spoons) described in the main text is unambiguous proof of the quality and homogeneity of the electrodeposited MDM stacks.

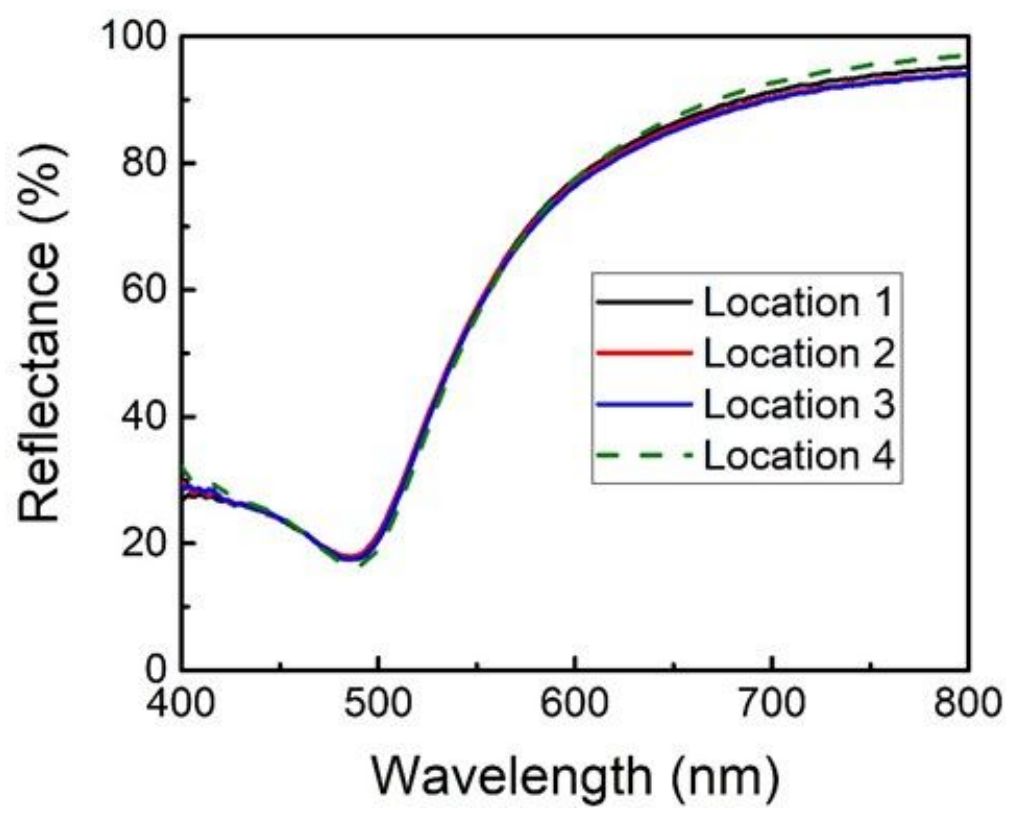

Figure S3. Measured reflectance spectra of yellow colored device at four separate locations. 


\section{S4. Cyclic Voltammetry}

The current-potential characteristics for both an $\mathrm{n}^{+} \mathrm{Si}(111)$ substrate and a stainless-steel spoon immersed in an aqueous solution of $0.1 \mathrm{mM} \mathrm{HAuCl}_{4} \cdot 3 \mathrm{H}_{2} \mathrm{O}, 1 \mathrm{mM} \mathrm{H}_{2} \mathrm{SO}_{4}, 1 \mathrm{mM} \mathrm{KCl}$, and 100 $\mathrm{mM} \mathrm{K}_{2} \mathrm{SO}_{4}$ are shown in Figure $\mathrm{S} 4$. These measurements were performed at $T=35^{\circ} \mathrm{C}$. The hump at $E=-0.8 \mathrm{~V}$ vs. $\mathrm{Ag} / \mathrm{AgCl}$ is associated to $\mathrm{O}_{2}$ reduction. Based on these voltammetric responses, $\mathrm{Au}$ electrodeposition on $\mathrm{n}^{+} \mathrm{Si}$ (111) substrates were performed at $\mathrm{E}=-1.9 \mathrm{~V}$ vs. $\mathrm{Ag} / \mathrm{AgCl}{ }^{6}$ Whereas, Au electrodeposition on stainless-steel spoons was performed at E = -1.4 V vs. Ag/AgCl. This was done to avoid excessive hydrogen evolution reaction.

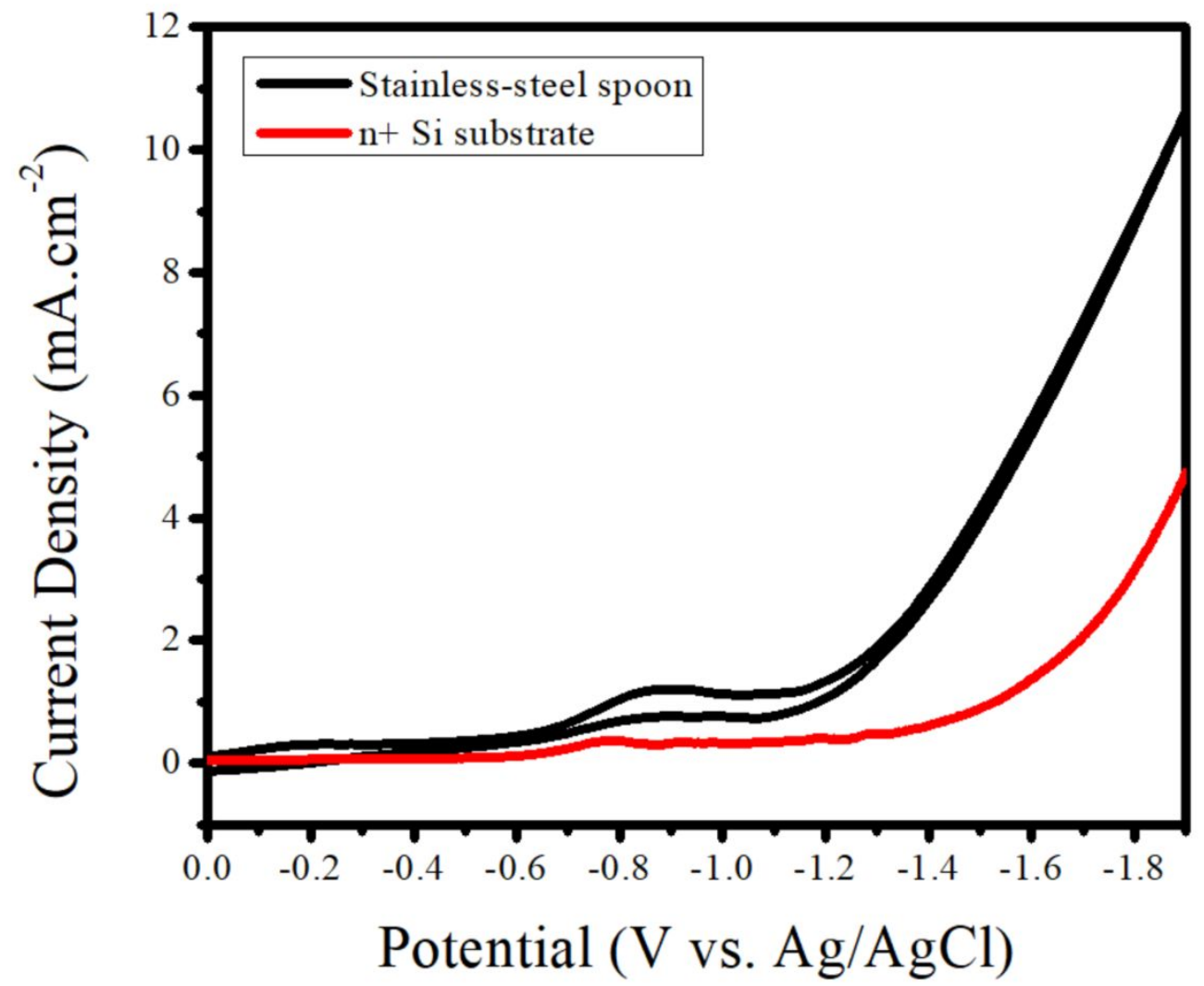

Figure S4. Cyclic Voltammetry response of an $\mathrm{n}^{+} \mathrm{Si}(111)$ electrode and a stainless-steel spoon electrode in $0.1 \mathrm{mM} \mathrm{HAuCl}_{4} \cdot 3 \mathrm{H}_{2} \mathrm{O}, 1 \mathrm{mM} \mathrm{H}_{2} \mathrm{SO}_{4}, 1 \mathrm{mM} \mathrm{KCl}$, and $100 \mathrm{mM} \mathrm{K}_{2} \mathrm{SO}_{4}$. Scan rate $=$ $50 \mathrm{mV} \mathrm{s}^{-1}$. 


\section{S5. References}

1. Eskhult, J.; Nyholm, L., Pulsed Galvanostatic and Potentiostatic Electrodeposition of $\mathrm{Cu}$ and $\mathrm{Cu} 2 \mathrm{O}$ Nanolayers from Alkaline Cu(II)-Citrate Solutions. J. Electrochem. Soc. 2008, 155, D115D122.

2. Switzer, J. A.; Hung, C.-J.; Huang, L.-Y.; Miller, F. S.; Zhou, Y.; Raub, E. R.; Shumsky, M. G.; Bohannan, E. W., Potential oscillations during the electrochemical self-assembly of copper/cuprous oxide layered nanostructures. J. Mater. Res. 2011, 13, 909-916.

3. Switzer, J. A.; Hung, C.-J.; Huang, L.-Y.; Switzer, E. R.; Kammler, D. R.; Golden, T. D.;

Bohannan, E. W., Electrochemical Self-Assembly of Copper/Cuprous Oxide Layered Nanostructures. J. Am. Chem. Soc. 1998, 120, 3530-3531.

4. Bohannan, E. W.; Huang, L.-Y.; Miller, F. S.; Shumsky, M. G.; Switzer, J. A., In Situ Electrochemical Quartz Crystal Microbalance Study of Potential Oscillations during the Electrodeposition of $\mathrm{Cu} / \mathrm{Cu} 2 \mathrm{O}$ Layered Nanostructures. Langmuir 1999, 15, 813-818.

5. Mishina, E. D.; Nagai, K.; Nakabayashi, S., Self-Assembled Cu/Cu2O Multilayers: Deposition, Structure and Optical Properties. Nano. Lett. 2001, 1, 401-404.

6. Prodhomme, P.; Warren, S.; Cortès, R.; Jurca, H. F.; Maroun, F.; Allongue, P., Epitaxial Growth of Gold on H-Si(111): The Determining Role of Hydrogen Evolution. Chemphyschem 2010, 11, 2992-3001. 